\title{
CREATING THE AUTHORIAL SELF IN ACADEMIC TEXTS: EVIDENCE FROM THE EXPERT'S STYLE OF WRITING
}

\author{
Tatiana Szczygłowska \\ University of Bielsko-Biala, Poland
}

\begin{abstract}
This paper reports on an analysis of stance expressions in a 439,490-word corpus of Ken Hyland's academic prose, encompassing 64 single-authored texts from journals, edited collections and his own monographs. Using WordSmith Tools 6.0, the study aims to find out how this expert academic writer creates his authorial self through stance mechanisms. The results reveal that Hyland's authorial participation in his discourse is mostly manifested through hedges, somewhat less definitely through boosters, but relatively infrequently by attitude markers and self-mention. The choice of the specific stance devices indicates a preference for detached objectivity when formulating empirically verifiable propositions and a shift towards subjectivity when referring to discourse acts and research methodology. These findings contribute to our understanding of stance-taking expertise in applied linguistics and may thus assist novice writers in the field in a more effective management of their own performance of self in academic prose.
\end{abstract}

Keywords: academic prose, authorial self, stance expressions, corpus analysis, Ken Hyland

\section{Article history:}

Received: 24 April 2020;

Reviewed: 28 April 2020

Revised: 24 May 2020;

Accepted: 25 May 2020;

Published: 30 June 2020

Copyright (c) 2020 Tatiana Szczygłowska

This open access article is published and distributed under a CC BY-NC 4.0 International License which permits non-commercial use, distribution, and reproduction in any medium, provided the original author and source are credited. Permissions beyond the scope of this license may be available at tszczyglowska@ath.bielsko.pl. If you want to use the work commercially, you must first get the authors' permission.

Citation: Szczygłowska, T. (2020). Creating the Authorial Self in Academic Texts: Evidence From the Expert's Style of Writing. English Studies at NBU, 6(1), 69-94. https:// doi.org/ 10.33919/ esnbu.20.1.3

Tatiana Szczygłowska holds a PhD in Linguistics. She is currently Assistant Professor at the Institute of Neophilology, University of Bielsko-Biala, Poland. Her main research interests lie in linguistics and translation with special focus on academic discourse and corpus linguistics. She has also conducted studies in the area of students' attitudes to target language culture and pronunciation.

E-mail: tszczyglowska@ ath.bielsko.pl

https:// orcid.org/ 0000-0002-5051-4080 
This article was inspired by Ken Hyland's presentation at the 2011 PRISEAL Conference on publishing and presenting research internationally, in which he examined how two leading applied linguists, John Swales and Debbie Cameron, construct their scholarly identity through discourse choices. Hyland (2015) later described this study in one of his papers, similarly as the analysis of John Swales' style of writing (Hyland, 2008). These articles motivated the undertaking of a similar project on the scholarly output of Ken Hyland himself, a renowned applied linguist who 'has had a large role in unveiling the interpersonal forces driving academic communication' (Dueñas, 2013, p. 2846). An important area of inquiry in Hyland's research is his model of writer-reader interaction based on the notions of stance and engagement (Hyland, 2005c). The former category has been selected as the topic of this study, as it concentrates on the writer and their expression of 'textual 'voice' or community recognized personality' through the resources for self-reference and for the presentation of attitudes, evaluations and commitments to potential readers (Hyland, 2005c, p. 176). Besides, due to the limited scope of the paper, it would be difficult to also do justice to the latter category.

Academic stance has been a popular focus of research; however, such investigations are often based on texts, the authors of which remain faceless. Hence, general trends in stance taking are highlighted, as observed in different disciplines (e.g., Pho, 2013), cultures (e.g., Abdollahzadeh, 2011), professional genres (e.g., Hyland, 2004), periods of time (e.g., Hyland \& Jiang, 2016), groups of (non-)native speakers (e.g., Dontcheva-Navrátilová, 2009) or (non-)novice academics (e.g., Wang \& Jiang, 2018). Less attention has been devoted to the textual analyses of the individual performance of eminent scholars, such as the above-mentioned ones by Hyland or the study by Önder (2012) who compared selected elements of metadiscourse, as used by John Swales and Ken Hyland. Still, as Hyland (2004, p. 149) asserts, 'the insights gained from examining how writing is constructed, interpreted, and used by experienced members of the community' may 'help us understand the nature of disciplinary identities and the meaning of expertise in particular fields' (Hyland, 2015, p. 304). This, in turn, is likely to help novice writers develop the desired conventions of stance taking that are integral to academic success. 
Adopting a more fine-grained perspective on these issues, the paper investigates prominent stance devices in a corpus of Ken Hyland's published writing, attempting to reveal which exponents of 'personal attitudes and assessments of the status of knowledge' actually help him achieve credibility as a disciplinary insider (Hyland \& Jiang, 2016, p. 253). Based on the scholar's recent paradigm of stance (Hyland, 2005c), the focus is on such stance markers as boosters, hedges, attitude markers and selfmention with respect to their: (1) frequency, (2) prominence in the corpus, (3) individual patterns of use, as well as (4) the reasons and implications underlying these tendencies. The aim is twofold: to see how Hyland exploits stance-taking resources to his own advantage, and to highlight the key aspects of his expert performance, attempting to foster stance awareness among novice academics.

\section{Stance in academic writing}

Academic persuasion goes beyond the mere communication of observable facts. What lies at its heart is, as Hyland (2019, p. 92) argues, 'the attempt to anticipate and head off possible objections to arguments'. Language choices have to be made carefully, as they give shape to the author's textual persona and help to validate the conveyed meanings with other partners in the discourse. Skilful use of language and tactful negotiation of rhetorical space, in which effective claims can be made as well as contested and then reframed, are all part of a process towards presenting the writer and their research as scientifically plausible and in line with the respective disciplinary community and its standards. The discoursal construction of what Clark and Ivanič (1997, p. 137) label as the 'authorial self' is manifested in the extent to which writers intrude into their texts 'to stamp their personal authority onto their arguments or step back and disguise their involvement' (Hyland, 2005c, p. 176).

To accomplish the mentioned aims, writers use a variety of rhetorical and linguistic resources that have been discussed in the literature under many different conceptual terms, a comprehensive overview of which can be found in Gray and Biber (2012), Pho (2013) or Hyland and Jiang (2016). Two important labels are 'evidentiality' (Chafe, 1986), connoting the writer's assessment of how they know their propositions are true, and 'affect' (Ochs and Schieffelin, 1989), denoting the subjective experience of feelings, moods or attitudes towards entities. Hyland and Jiang (2016) explain that these two concepts are often integrated into a single model, as reflected in Biber and 
Finegan's (1989) conceptualization of 'stance' in terms of assessments of the status of knowledge as well as personal attitudes and emotions. Biber, Johansson, Leech, Conrad and Finegan (1999) developed this framework, proposing a distinction between attitudinal stance (affect) and epistemic stance (evidentiality), as well as adding the category of style of speaking, concerned with the writer's comments on the communication. Another important approach to these issues is 'evaluation' (Hunston \& Thompson, 2000) that centres around the writer's evaluations of value (evaluations of characteristics), status (degree of certainty invested in information), expectedness (obviousness to the reader) and relevance (significance to the reader) of what they discuss. Closely related is also the model of 'appraisal' (Martin \& White, 2005), which encompasses three systems: attitude that encodes affect (emotional responses), appreciation (aesthetic evaluations) and judgement (moral evaluations); engagement that aligns with epistemic stance meanings; and graduation that is concerned with the strength of evaluative positions.

Added to the above are Hyland's own conceptions of stance which are largely consistent with the mentioned approaches. In his early works, Hyland (1998a, 1998b) sees stance as constructed through hedges and boosters expressing various degrees of certainty and conviction. Later on, he starts to conceive of stance in terms of three components: evidentiality that concerns the writer's commitment to the truth of their propositions, affect that involves the manifestation of personal and professional attitudes towards what is said, and relation that refers to the writer's self-presentation and engagement with the readers (Hyland, 1999). Hyland's work on these issues also falls under the umbrella term 'metadiscourse' (Hyland, 2005a), in the framework of which stance relates to interactional resources that help to manage writer-reader interactions in texts. Hyland (2005c) further elaborates interactional metadiscourse, reframing it as two clear-cut dimensions: stance, which conveys the writer's attitudes and evaluations, and engagement, which relates to addressing the reader directly.

In Hyland's (2005c, p. 178) latter conception, adopted in this study, stance concerns 'the ways academics annotate their texts to comment on the possible accuracy or credibility of a claim, the extent they want to commit themselves to it, or the attitude they want to convey to an entity, a proposition, or the reader'. Stance features show the authorial presence and are thus writer-oriented, as opposed to engagement features, 
which acknowledge the presence of readers and are thus reader-oriented. They provide important insights into the rhetorical choices through which writers convey 'epistemic and affective judgements, opinions and degrees of commitment to what they say' (Hyland, 2009, p. 111). Similarly as in Hyland's (1999) earlier conception, in this new model stance encompasses evidentiality and affect, but the category of relation has been replaced with presence that 'concerns the extent to which the writer chooses to project him or herself into the text' (Hyland, 2005c, p. 178). The resources carrying these meanings fall into four sub-categories: hedges and boosters (evidentiality), attitude markers (affect) and selfmentions (presence). They help writers to elaborate their own positions and fulfil a "dialogic purpose in that they refer to, anticipate, or otherwise take up the actual or anticipated voices and positions of potential readers" (Hyland, 2005c, p. 176).

This particular approach to stance is adopted in the study as it is fairly recent but widely used, clear and simple, and additionally, it builds on previous taxonomies (Abdi, Tavangar Rizi \& Tavakoli, 2010). It seems to encompass Biber et al.'s (1999, p. 966) 'authorial stance', seen as the writer's 'personal feelings, attitudes, value judgments, or assessments' of the propositional content or other scholars, and 'authorial presence', manifested through the use of self-reference expressions to claim identity or authority (Clark \& Ivanič, 1997). As Pho (2013, p. 22) explains, such conceptualization of stance is more comprehensive, as it 'includes various dimensions: personal versus impersonal, present versus absent, overt versus covert, explicit versus implicit, subjective versus objective, involved versus detached, or concrete versus abstract'. It also incorporates the idea that academic writing does not take place in a vacuum but is rather put through the lens of disciplinary readers. Thus, in seeking approval for their claims, academic writers engage in dialogic interaction with their audience, trying to orient them towards the desired interpretations, while simultaneously creating a discursive space for their imagined reactions to those interpretative stimuli.

As already mentioned, the linguistic means of marking stance have been divided by Hyland (2005c: 178-181) into four categories, all of which facilitate the achievement of interpersonal goals. Hedges (e.g., possible, could, perhaps) convey tentativeness and possibility, enabling the writer to reduce the level of their commitment to propositions. Statements are no longer seen as accredited facts but rather as plausible opinions that are still subject to negotiation, depending on how alternative the readers' perspectives 
are. Hedges allow room for disagreement for they mark research results as indicative and not definitive, in fact contributing to their precise reporting by 'projecting honesty, modesty and proper caution in self-reports' and 'diplomatically creating space in areas heavily populated by other researchers' (Swales, 1990, p. 175). They constitute an effective tool for academic writers to signal subjective assessment of the reliability of their claims, while protecting themselves from being proved wrong, which is possible owing to the potential that hedges have for accommodating readers' feedback and manipulating them into agreement.

Boosters (e.g., certainly, obviously, clearly) express conviction and certainty, enabling the writer to forcefully assert propositions. When the propositional content is presented more categorically, a marked authorial voice is promoted. This, admittedly, closes the discursive space for competing views but persuades readers of the relevance of findings that would not be reported so confidently if their reliability could not be sufficiently guaranteed. The presence of boosters gives the impression that the author is heavily involved with the topic and is thus licensed to act as a disciplinary authority whose conclusions can be shared. Readers are thus invited to become a part of the discussion on the strength of their awareness of certain self-evident details, which seems to constitute an implicit assumption in a more assured and confident discourse. Together, hedges and boosters activate those 'aspects of language use' that are 'generally referred to as epistemic: they enable writers to express their assessment of possibilities and indicate the degree of confidence in what they say' (Hyland \& Milton, 1997, p. 183).

Attitude markers (e.g., dramatic, desirable, surprising) reflect the writer's affective attitude to the propositional information, clarifying their emotions, feelings or degree of importance attached to the subject matter and its audience. The use of attitudinals in a text contributes to creating interpersonal solidarity, as 'by signalling an assumption of shared attitudes, values and reactions to material, writers both express a position and pull readers into a conspiracy of agreement so that it can often be difficult to dispute these judgements' (Hyland, 2005c, p. 180). An appropriate personal evaluation of what is presented in the discursive space can favourably dispose the reader towards the author's claims, especially if the latter have been formulated in line with 'the value system of the particular community they address' (Dueñas, 2010, p. 51). 
Self-mention (e.g., I, my, the author) is defined by Hyland (2001a, p. 207) as 'the extent to which writers can explicitly intrude into their discourse' to report 'propositional, affective and interpersonal information' (Hyland, 2005c, p. 181). Authors consciously decide whether to include or exclude direct personal reference to themselves or their research. What prompts them to do so is the desire to direct readers through a text towards the desired interpretations while simultaneously highlighting their own role as researchers and seeking acceptance for their scientific endeavours.

The degree of authorial investment that writers realize in academic prose reveals not only how skilful they are at managing the textual structuring of the language or what preferences they have for the specific linguistic means of expression. The different modes of authorial projection are also indicative of how confident writers feel as researchers, disciplinary insiders and partners in a discursive exchange of perspectives, the negotiation of which is crucial to academic success. The constellation of rhetorical choices made to stamp one's persona on their texts constitutes a benchmark of their individual writing performance that is geared to give shape to the assertions presented and win readers' approval. Yet, to ensure the latter, the writer needs to engage disciplinary readers in the discussion by employing a compelling configuration of stance devices.

\section{Corpus and method}

The Hyland corpus (HC) consists of 64 single-authored texts, comprising 48 research articles, 14 book chapters (see Appendix), the monograph Disciplinary Discourses (2000/2004) and theoretical fragments from English for Academic Purposes (2006). The collected documents were modified by removing those fragments that could not be considered as the author's own discourse (e.g., block and longer in-text quotations, examples, tables and other figures, references). Subsequently, they were converted to plain-text format, bringing the total of 439,490 words.

The corpus was scanned with WordSmith Tools 6 (Scott, 2012) for occurrences of 228 common stance devices (91 hedges, 64 boosters, 62 attitude markers, 11 selfmentions), the list of which was adapted from Crosthwaite, Cheung and Jiang (2017). The scholars' choice of items matches that of Hyland (2004) and additionally incorporates different variant forms of a given stance device, which makes it comparable with Hyland's (2005a) list of interactional metadiscourse items. 
Simultaneously, Crosthwaite et al.'s (2017) list is less extensive and thus it better suits the limited scope of this study. The devices were then categorized into three sets, depending on their overall frequency in the corpus. The 'Freq. 0' set comprised 54 devices which did occur even once, the 'Freq. $<25$ ' set comprised 70 devices which occurred less than 25 times, and the 'Freq. $\geq 25$ ' set comprised 104 devices which occurred at least 25 times, with certain exceptions. Specifically, if a given item had its variant forms, they were also included in the latter set, even if their rate of occurrence was lower, for example, possible with 263 tokens and possibly with 9 tokens were both included. Subsequently, the 'Freq. $\geq 25$ ' set was examined through a close reading of its items' concordance lines to eliminate those occurrences that did not function as stance markers. The final list comprised 93 frequent items that were examined in context to capture the main aspects of Hyland's projection of authorial stance.

\section{Data analysis and discussion}

\section{Overall frequency}

Table 1 shows the overall picture of the Hyland corpus content in terms of stance expressions, which have been arranged in decreasing order of frequency. Underlining marks the variant forms that were included in the 'Freq. $\geq 25$ ' set because of the high frequency of their co-forms. The italicized items were eliminated from further study, as their concordances revealed that they rarely functioned as stance markers.

\section{Table 1}

Stance Devices Searched in the Hyland Corpus

\begin{tabular}{|c|c|c|}
\hline Freq. 0 & Freq. $<25$ & Freq. $\geq 25$ \\
\hline \multicolumn{3}{|c|}{ Attitude markers $(\mathrm{N}=62)$} \\
\hline $\begin{array}{l}\text { agreed, amazed, amazingly, } \\
\text { astonished, astonishing, } \\
\text { astonishingly, desirably, } \\
\text { disappointingly, disagrees, } \\
\text { disagreed, expectedly, } \\
\text { fortunate, fortunately, } \\
\text { hopeful, inappropriately, } \\
\text { preferable, shocked, } \\
\text { shocking, shockingly, } \\
\text { unbelievable, unbelievably, } \\
\text { unexpectedly, unfortunate }\end{array}$ & $\begin{array}{l}\text { striking, unfortunately, } \\
\text { dramatically, disagree, } \\
\text { admittedly, unusual, usual, } \\
\text { correctly, dramatic, } \\
\text { hopefully, remarkable, I } \\
\text { agree, disappointed, } \\
\text { strikingly, understandable, } \\
\text { agrees, desirable, } \\
\text { preferably, remarkably, } \\
\text { understandably, curious, } \\
\text { disappointing, unusually }\end{array}$ & $\begin{array}{l}\text { important, appropriate, } \\
\text { even x, interesting, } \\
\text { expected, appropriately, } \\
\text { importantly, essential, } \\
\text { surprisingly, interestingly, } \\
\text { surprising, inappropriate, } \\
\underline{\text { unexpected }} \text { surprised } \\
\text { preferred, prefer }\end{array}$ \\
\hline
\end{tabular}




\begin{tabular}{|c|c|c|}
\hline \multicolumn{3}{|c|}{ Boosters $(\mathrm{N}=64)$} \\
\hline $\begin{array}{l}\text { beyond doubt, } \\
\text { incontestable, } \\
\text { incontestably, } \\
\text { incontrovertible, } \\
\text { incontrovertibly, } \\
\text { indisputable, indisputably, } \\
\text { realizes, surely, truly, } \\
\text { undeniable, undeniably, } \\
\text { undisputedly, without } \\
\text { doubt }\end{array}$ & $\begin{array}{l}\text { believed, know, I/we } \\
\text { believe, really, no doubt, } \\
\text { find that, proved, definitely, } \\
\text { definite, sure, prove, finds, } \\
\text { believes, doubtless, } \\
\text { undoubtedly, knew, found } \\
\text { that, conclusively, } \\
\text { decidedly, known, proves }\end{array}$ & $\begin{array}{l}\text { clearly, shows, the fact that, } \\
\text { always, show, must, } \\
\text { establish, in fact, actually, } \\
\text { of course, obviously, } \\
\text { demonstrate, shown, } \\
\text { obvious, think, showed, } \\
\text { indeed, certainly, never, } \\
\text { true, established, it is clear, } \\
\text { demonstrates, thought, } \\
\text { demonstrated, thinks, } \\
\text { certain that }\end{array}$ \\
\hline \multicolumn{3}{|c|}{ Hedges $(\mathrm{N}=91)$} \\
\hline $\begin{array}{l}\text { certain extent, couldn't, } \\
\text { from our perspective, from } \\
\text { my perspective, in most } \\
\text { instances, in my view, in } \\
\text { our view, in my opinion, in } \\
\text { our opinion, postulated, } \\
\text { postulates, presumable, } \\
\text { supposes, to my } \\
\text { knowledge, uncertainly, } \\
\text { unclearly, wouldn't, }\end{array}$ & $\begin{array}{l}\text { probably, roughly, unclear, } \\
\text { suspect, somewhat, } \\
\text { presumably, suppose, } \\
\text { supposed, in this view, } \\
\text { certain amount, around, in } \\
\text { most cases, ought, guess, } \\
\text { estimate, estimated, } \\
\text { suspects, from this } \\
\text { perspective, certain level, } \\
\text { approximately, maybe, on } \\
\text { the whole, mostly, } \\
\text { postulate, probable }\end{array}$ & $\begin{array}{l}\text { often, may, mainly, might, } \\
\text { perhaps, likely, generally, } \\
\text { possible, largely, typically, } \\
\text { almost, suggests, relatively, } \\
\text { suggest, frequently, tend to, } \\
\text { essentially, seems, about, } \\
\text { indicate, tended to, seem, } \\
\text { would, rather x, usually, } \\
\text { could, appears to, } \\
\text { suggested, plausible, } \\
\text { sometimes, tends to, } \\
\text { assume, appear to, broadly, } \\
\text { apparently, fairly, indicates, } \\
\text { seemed, uncertain, } \\
\text { assumed, assumes, } \\
\text { unlikely, appeared to } \\
\underline{\text { indicated, in general, }} \\
\text { possibly, plausibly, it } \\
\underline{\text { appears that }} \\
\text { evident, evidently }\end{array}$ \\
\hline \multicolumn{3}{|c|}{ Self-mention $(N=7)$} \\
\hline & & $\begin{array}{l}\text { I, my, me, mine } \\
\text { we, our, us } \\
\text { the author, the author's } \\
\text { the writer, the writer's }\end{array}$ \\
\hline
\end{tabular}

Overall, 14 (22.58\%) of the attitude markers searched, 27 (42.19\%) of boosters, $48(52.75 \%)$ of hedges and $4(36.36 \%)$ of self-mentions were considered as characteristic of Hyland's expression of stance and subjected to further study. This gives 
the total of 93 stance devices, $51.61 \%$ of which are hedges, $29.03 \%$ are boosters, $15.05 \%$ are attitude markers and $4.3 \%$ are self-mentions. Regarding the total occurrence of these features and the values of their frequency normalized to 1,000 words, shown in Table 2, hedges are Hyland's first choice, followed by boosters, attitude markers and the least preferred self-mention.

\section{Table 2}

Distribution of the Most Frequent Stance Devices in the Hyland Corpus

\begin{tabular}{lcccc}
\hline & Self-mention & Attitude markers & Boosters & Hedges \\
\hline Raw frequency & 1081 & 1279 & 2514 & 5882 \\
Per 1,000 words & 2.45 & 2.91 & 5.72 & 13.38 \\
\hline
\end{tabular}

Hyland's preferences for stance features are largely consistent with the trends commonly observed in academic writing in general as well as with the ones that are typical of the soft disciplines (see Yu, 2019), which he himself represents. This concerns especially his strong inclination for using hedges that 'are among the highest frequency content words in academic writing' (Hyland, 2005b, p. 105), particularly in the humanities (Hyland 1999). Boosters are also common in the soft sciences (Hyland, 2008; 2011), whereas attitude markers are usually less frequent (Abdollahzadeh, 2011), similarly as person markers (Hyland, 2004).

\section{Self-mention}

Self-reference $(\mathrm{N}=4)$ is the least frequent stance device in the Hyland corpus, as it occurs 2.45 times per 1,000 words (see Table 2). It should be noted that we, our and us were excluded from further analysis, as only 8 instances out of 2279 were identified as exclusive (1), that is, belonging to the category of self-mention, while the rest were inclusive (2) and functioned as engagement markers (see Hyland, 2005a).

(1) The fact that we have examined a number of these features elsewhere in this book [...] (2000/2004)

(2) [...] knowledge, disciplines and the professional careers of academics themselves are ultimately constructed through the ways we write. (172)

Comparably rare is the use of the third person for authorial self-reference, as none of 900 tokens of the author, the author's, the writer or the writer's were identified 
as subjective. Apparently, Hyland readily identifies his 'public persona as an academic' with 'the private "I" persona' (Sanderson, 2008, p. 157), which makes I (818 tokens), my (243), me (19) and mine (1) the main means of self-representation. Hyland's overt presence in his texts correlates with the rhetorical apparatus of humanities prose which puts emphasis on 'establishing an appropriately authorial persona' to effectively probe 'relationships and connections with the entities that are generally more particular, less precisely measurable, and less clear-cut than in the' non-soft disciplines (Hyland, 2001a, p. 216). Besides, recently there has been a shift from using we to using $I$ as the preferred marker in applied linguistics' (Hyland \& Jiang, 2016, p. 267).

The most frequent lexical verb collocates of I, occurring within the span of three words to the right, constitute discourse verbs (111 tokens): discuss (48), note (23), suggest (20), focus on (20). Then, there are cognitive verbs (72 tokens): want (50), hope (22) and the least frequent are research verbs (65 tokens): explore (42), examine (23).

(3) I discuss my approach to texts in detail in Chapter 7 [...] (2000/2004)

(4) First, I want to provide some theoretical background as a context for what follows [...] (2000/2004)

(5) In this article I briefly explore the most visible expression of a writer's presence in a text: $[\ldots](70)$

Considering the semantic characteristics of the above verbs, it seems that Hyland explicitly links himself with 'the verbal expression of research or cognitive activities', but less readily with his own mental activities or 'experimental actions or procedures' (Ling Lin, 2020, p. 68). This preference for discourse acts is his expression of disciplinary voice, since frequent use of such verbs has been reported as typical of applied linguistics (Hyland, 2001b). The soft disciplines are discursive rather than experimental by nature, therefore writers 'must rely far more on focusing readers on the claim-making negotiations of the discourse community, the arguments themselves, rather than relatively unmediated real-world phenomena' (Hyland, 1998a, p. 361).

However, Hyland's choice of verbs accompanying the pronoun I may also appear as ambivalent. Sometimes his discourse voice is presented somewhat tentatively through a stance of academic modesty, as in (6) and (7), while in other sentences he expresses volition, making his voice 'more persuasive and more easily shared with the 
reader/ audience', as in (8) (Belladelli, 2009, p. 310). Also, the verbs hope and want mark attitudinal stance, reflecting the writer's private state of desire in relation to the different discourse activities (Fortanet-Gómez, 2004).

(6) In reality, as I hope the previous analyses have suggested, [...] (2000/2004)

(7) In this section, I have suggested how writers draw in their readers to engage them $[\ldots](65)$

(8) As an illustration of corpus research, I want to consider a study which attempts to see $[\ldots](184)$

The most frequent collocates of my, occurring within the span of three words to the right, belong to the category of research nouns. The largest group constitute words denoting research participants (67 tokens): informant(s) (53), respondents (10), interviewees (4), and the remaining items (52 tokens) include: corpus (22), analysis/ es (8), research (8), method(s) (4), data (4), discussion (3), study (3). As Charles (2004, p. 210) claims, research nouns help to construct 'a stance of objectivity and impersonality', but the writer may wish 'to retain some responsibility' for the elements of research methodology, which is achieved by combining these nouns with explicit self-mention, as shown below.

(9) In my corpus these texts were generally composed of fewer moves [...] (88)

(10) My analysis shows that writers are not responding to creative whim [...] (2000/2004)

(11) This was made clear by several of my disciplinary informants during the interviews: (97)

\section{Attitude markers}

Attitude markers ( $\mathrm{N}=14$ ) in the Hyland corpus occur 2.91 times per 1,000 words which makes them only slightly more popular than self-mention and twice less frequent than boosters (see Table 2). This finding is in line with Conrad and Biber's (2000, p. 68) claim that attitudinal resources are 'moderately common' in academic prose. It also reflects the tendency observed by Hyland and Jiang (2016), according to whom nowadays applied linguists employ attitudinals twice as infrequently as boosters. 
The most frequent attitude markers include: important (522 tokens), appropriate (271), even $x$ (144), interesting (88) and expected (55). This finding is corroborative of previous data by Hyland and Jiang (2016), who found that excepting appropriate, the other words were the main choice of applied linguists. Similar preferences were also reported by Akinci (2016) and Yu (2019). The item which seems to be unique to Hyland's individual way of marking attitudinal stance is appropriate, which is often employed to mean that something is suitable for the situation at hand (12) and to create the cluster shown in (13).

(12) Effective academic writing depends on appropriate language choices [...] (109)

(13) Respondents had greater difficulty in assigning an appropriate degree of certainty to hedges. (58)

Attitudes are most frequently signalled by adjectives (8 items, Freq. 953), followed by adverbs (5 items, Freq. 271), and verbs are the least frequent (1 item, Freq. $55)$, which corroborates previous research on the grammatical categories of attitudinals in applied linguistics (see Abdollahzadeh, 2011; Yu, 2019). Adjectives 'make up a large proportion of the vocabulary of evaluation' (Paquot 2010, p. 20) and 'play important cohesive, classificatory [...] roles' (Hinkel, 2004, p. 211). Therefore, they facilitate the demonstration of qualitative research in the soft fields and help in 'the logical comparison of alternatives and the use of persuasive form' that are integral to convincing humanities prose (Biber, 1988, p. 194). Examples illustrating how Hyland exploits these functions of adjectives are presented below.

(14) An emphasis on research features in these circumstances might therefore be an appropriate persuasive strategy rather than a departure from the norms of research writing. (127)

(15) The adjunct model, widely used in the US, is perhaps the most interesting of these three approaches to cross-curricular collaboration [...] (2006)

In another sentence, Hyland uses important to reveal his assumption about the propositional content, and then credits his readers with knowledge about the nature of concordances: 
(16) Concordances are important as they display all occurrences of a feature in its immediate co-text, [...], which enables functions to be identified and ambiguities clarified. (97)

The most strongly represented functional category of attitudinals is evaluation (6 items, Freq. 911), especially positive evaluation expressed by important(ly), appropriate(ly) and essential, more than the negative one conveyed only by inappropriate. These items are used to favourably evaluate Hyland's own (17) or others' work (18), and even more often to highlight the significance of the discussed issues (19).

(17) [...] I want to consider a study which attempts to see what corpus research can contribute to the study of identity [...] The study is important as it seeks to move away from [...] (184)

(18) More importantly, Halloran (1984) has argued that there is also an entrepreneurial spirit in the discipline [...] (78)

(19) As I have suggested, learning about genres that have accumulated cultural capital does not rule out critical analysis but provides an essential foundation for it. (21)

Another prominent category is affect (6 items, Freq. 307), signalled by even $x$, interesting(ly), surprising(ly) and surprised. The emotional tones and dispositions are adopted to research results (20), viewpoints of other scholars (21) or other phenomena discussed (22). The least represented are attitudinal markers of position (2 items, Freq. 61): (un) expected, which relate to 'the way authors position themselves and view works and arguments' (Yu, 2019, p. 81), as in (23).

(20) There was also a surprising use of full names for both friends and nonacademics, with over $90 \%$ in each category [...] (80)

(21) Killingsworth and Gilbertson (1992: 7) make the interesting point that communities are actually a kind of communication media in that they affect the manner and meaning of any message delivered through it. (2000/2004)

(22) Even applied linguistics has become increasingly implicated in the sociocultural struggles of the end-users of its research $(2000 / 2004)$

(23) Less frequent than expected in this corpus, perhaps, are moves which relate to the author's research and teaching. (157) 


\section{Boosters}

Boosters $(\mathrm{N}=27)$ occur 5.72 times per 1,000 words, which makes them the second most popular stance device in the Hyland corpus (see Table 2). This finding is comparable with the frequency of 6.2 reported by Hyland (1998a) in applied linguistics papers. The fact that the frequency of boosters reported here is smaller than the one reported by Hyland twenty years ago may reflect a general decrease in their use by applied linguists in recent years that was observed by Hyland and Jiang (2016).

The most frequent items increasing the force of claims are verbs (13 items, Freq. 1093), followed by adverbs (8 items, Freq. 921), then by phrases (3 items, Freq. 401) and adjectives ( 3 items, Freq. 99). These findings are in line with the results obtained by Yu (2019) and partly corroborate those reported by Abdollahzadeh (2011), who found that the most frequent boosters in his corpus of applied linguistics papers were modal verbs and adverbials, followed by verbs and adjectives. In the Hyland corpus, the most frequent boosters are clearly (299 tokens), shows (236), the fact that (223), always (218) and show (200).

Verbal boosters include: show*1 (523 tokens), must (193), establish* (186), demonstrate* (123) and think* (68). As Hyland (2004, p. 90) claims, show, demonstrate and establish involve 'the discursive presentations of evidence' that is declared as true based on the convincing nature of the study results rather than on the persuasive skills of the writer, as in (24) and (25). These verbs are often reported as very frequent in academic writing (Peacock, 2006; Hyland, 2004) and, as Hyland and Jiang (2016) conclude, especially the first two have recently become even more popular in applied linguistics than before. The scholars also noted a decline in the use of the cognitive verb think, which is moderately frequent in the Hyland corpus, as well. The reason may be that the certainty implied by think is subjective, as it results from personal belief, not from the evidential nature of the data, as in (26). This rhetorical evasion is nevertheless compensated for by Hyland's use of the directive modal booster must, which carries a high degree of certainty and helps to manoeuvre between strong subjectivity (27) and detached objectivity (28). The latter accounts for $24.9 \%$ occurrences of must in the corpus, allowing Hyland to hide behind his assertions "by placing the syntactic focus on the theme' (Yu, 2019, p. 77).

\footnotetext{
1 The asterisk indicates different forms of the verb in the corpus.
} 
(24) The results also show some interesting cross-discipline comparisons. (139)

(25) My analyses demonstrate that social context always impinges on the discourses of the academy [...] (2000/2004)

(26) It was thought that this list would provide a broad international base of comparable institutions from which to collect data for the study. (157)

(27) An effective response to this view must therefore involve (i) encouraging students to [...] (70)

(28) Here hedges must be seen as part of a wider process of creating and crafting complete texts, [...] (38)

Boosters in the form of adverbs are dominated by items that convey a high degree of certitude in a proposition along with a mutual understanding between the author and the reader, emphasizing shared information and discourse community membership (Hyland, 1998a). The boosters that express such meanings were attested 568 times and include not only the adverbs clearly (299 tokens), of course (95) and obviously (82), but also the adjective obvious (64) and the phrase it is clear (28). As Simon-Vandenbergen and Aijmer (2007) claim, clearly, which is authority-oriented, is more popular in writing than the more solidarity-oriented obviously, yet they both indicate that the writer's certainty results from evidence or generally accepted knowledge, as in (29) and (30). Hyland's frequent use of clearly may be also attributed to the fact that it 'tends to be used in discussions of data', which are, in principle, empirically grounded, similarly as Hyland's applied linguistic analyses (Rozumko 2017, p. 86). Of course is linked to politeness and solidarity' (Szczyrbak 2014, p. 98) and the certainty it expresses stems from 'the fact that the state of affairs is in accordance with expectations' (Simon-Vandenbergen \& Aijmer, 2007, p. 81). This can be seen in (31), where Hyland politely explains why risk is involved in the discussed tactic. By comparison, in (32) Hyland exploits the authoritarian nature of the adverb, which may also imply 'as everybody knows or should know', assuming that the reader knows that written scientific output is generally high (Simon-Vandenbergen \& Aijmer, 2007, p. 219-220).

(29) The percentage distribution of appraisal shows clearly how the disciplines separated along the hard-soft knowledge divide. (2000/2004)

(30) Obviously everyone is different. Social class, ethnicity, gender, age and so on influence how we make sense of our disciplines [...] (215) 
(31) This tactic is not without risks, of course, as it can violate the conventional fiction of democratic peer relationships diligently cultivated in published research writing. (65)

(32) A huge number and variety of texts are, of course, produced by the academy and, [...] (2000/2004)

Other frequent expectation markers are in fact (150 tokens) and actually (114), which convey 'assertion in reality' (Hoye, 1997, p. 184) and 'involve some kind of online matching of knowledge against a prior pattern' (Chafe 1986, p. 271). Contrary to the adverbs discussed above as well as such items as indeed (40) and certainly (38), those concerned with actuality 'do not express conviction or high probability but counterexpectation' (Simon-Vandenbergen \& Aijmer, 2007, p. 70). The examples below show how Hyland incorporates in his writing the suggestions that some fact goes beyond what might have been expected, trying simultaneously to remain polite to his readers.

(33) Learning about genres does not preclude critical analysis. In fact it provides a necessary basis for critical engagement with cultural and textual practices, [...] (2006)

(34) I get the impression that teachers often see genre as a research tool rather than a teaching one, but this is a misconception. Genre is actually a robust pedagogical approach [...] as it serves a key instructional purpose: that of illuminating the constraints of social contexts on language use. (130)

Another frequent booster is the fact that (223 tokens). Its popularity as a means of expressing stance in academic writing has been confirmed by many researchers, including Hyland (1998a) himself, who reported it as the second most frequent booster in a general academic corpus, as well as Peacock (2006), who reported it as the fourth most frequent booster in language and linguistics. According to Jiang and Hyland (2015, p. 532), the phrase is 'a powerful persuasive device as the choice of noun foregrounds an author's assessment of the reliability of what follows and indicates to readers how the material should be understood'. The scholars also note that fact is the third most popular stance noun in this construction among applied linguists. As for Hyland, it is his preferred noun, since none of the other ones listed by Jiang and Hyland (2015) as frequent in applied linguistics had a comparable number of occurrences in the study corpus. Hyland often uses the fact that to comment on an evidential reality, as in (35), 
and only sometimes to convey a judgement of certainty, as in (36). Following Jiang and Hyland's (2015) explanation, in (36) the preposition despite denotes a contrast between the initial and the final part of the sentence, implying that the fact that expresses an epistemic evaluation commenting on the likely certainty of what the reader is oriented to by the fragment book publication [...].

(35) The second reason for the attention given to academic writing is the fact that what academics principally do is write: [...] (2000/2004)

(36) They [book reviews] also appear in a number of hard knowledge journals, despite the fact that book publication accounts for only a fraction of research output in these disciplines. (2000/2004)

\section{Hedges}

Hedges $(\mathrm{N}=48)$ are the most frequent category of stance in the Hyland corpus, as they occur 13.38 times per 1,000 words (see Table 2). This finding is corroborative of previous studies which reported common use of hedges in academic texts (see Hyland, 2005b; Abdollahzadeh, 2011; Yu, 2019), reflecting scholars' preference for prudence in reporting their research.

Hyland's claims are most often mitigated by adverbs (19 items, Freq. 2983), followed by verbs (23 items, Freq. 2291), then by adjectives (5 items, Freq. 598) and phrases (1 item, Freq. 10). This partly reflects the results reported by Yu (2019), who found adverbs to be the second most frequent category of hedges in applied linguistics, after modals but before lexical verbs. In the Hyland corpus, the most frequent hedges are often (870 tokens), may (572), might (308), perhaps (296) and likely (268).

When expressing caution through adverbs, Hyland often makes reference to the frequency of the propositional information, the precision of which cannot be categorically stated but can be empirically verified (5 items: often, typically, frequently, usually, sometimes; Freq. 1333), as in (37). He also readily comments on the indefiniteness of the degree to which the propositional information applies (7 items: generally, largely, relatively, mainly, rather $x$, broadly, fairly; Freq. 873), as in (38), sometimes employing the phrase in general (Freq. 10), as in (39). Tentative approximations of the precision with which the propositional content is presented are less common (3 items: almost, essentially, about; Freq. 422), as in (40), similarly as 
adverbs expressing degrees of probability (4 items: perhaps, apparently, possibly, plausibly; Freq. 355), as in (41).

(37) In this corpus, the conclusions typically reiterated the strongest claim made in the letter, summarising the main results [...] (2000/2004)

(38) The analyses show that [...] the written genres contained relatively few stance and organizing bundles. (184)

(39) In general, more reader oriented markers were found in the discursive soft fields, [...] (2000/2004)

(40) Overall, they [reader features] occurred about 32 times per article, almost two on every page. (65)

(41) Reader pronouns are perhaps the most explicit way that readers are brought into a discourse. (94)

Verbal hedging involves six lexical (Freq. 1265) and four modal verbs (Freq. 1026). The most frequent are tentative linking verbs (Freq. 622): tend ${ }^{*}$ to (278 tokens), as well as seem* (225) and appear* (119) that express epistemic evidentiality; followed by non-factive reporting verbs (Freq. 544): suggest* (401) and indicate* (143), and the least popular tentative cognition verb assume* (99), where the three latter verbs express epistemic speculative judgement (Hyland 1998b). Hyland uses these verbs for three main purposes: to present own (42) or other's (43) research and to tentatively qualify claims about the discussed issues (44). A relatively high proportion of such discourse-oriented verbs as suggest and indicate as well as infrequent use of cognition verbs testify to Hyland's preference for creating an objective discourse where prominence is given to the persuasive strength of data or methodological practice rather than the convictions of the interpreting writer', which, as Hyland and Jiang (2016, p. 270) argue, is a recent trend in the soft disciplines.

(42) [...] these writers tended to make explicit the kind of help they received, with only $1.5 \%$ of the thanking acts unclassifiable from the context. (88)

(43) Toulmin (1972) suggests that communities can be approximately arranged on a continuum from 'compact' to 'diffuse' [...] (2000/2004)

(44) Four-word bundles seem to be most often studied, [...] (164)

The most common modal auxiliary was may (572 tokens), followed by might (308), both of which are generally frequent in academic prose (see Hyland, 1998b), and then by the definitely less popular would (87) and could (59). Given the frequency with 
which may is used in the corpus, Hyland seems to prefer 'factual possibility' (45) over 'tentative possibility' (46), as expressed by might and could (Leech \& Svartvik, 1975, p. 111-112). In turn, employing would, Hyland usually conveys hypotheticality (47) and only sometimes a tentative assertion (48).

(45) In practice, these principles may be expressed in very different ways as genre approaches do not represent a single set of techniques. (116)

(46) It could be that these differences are related to rank rather than gender. (154)

(47) Removing these metadiscourse features would make the passage much less personal, less interesting, and less easy to follow. (142)

(48) The decision to adopt an impersonal rhetorical style or to represent oneself explicitly would seem to have significant consequences for how one's message is received. (63)

The adjectives through which Hyland expresses hedging all convey degrees of probability involved in the certainty or accuracy of the propositional content (5 items: likely, possible, plausible, uncertain, unlikely; Freq. 579), as in (49).

(49) While these self-reports offer plausible explanations for the different rhetorical practices of the disciplines, [...] (78)

\section{Conclusion}

This paper has examined how Ken Hyland constructs his authorial self through stance mechanisms, testifying to the expertise with which he manoeuvres in the discursive reality of his own field. Hyland frequently hedges his claims in response to the vagueness of soft-knowledge research, but orients readers' interpretation to factual rather than hypothetical possibility (see Leech \& Svartvik, 2002). Yet, he is aware that restrained commitment to propositions should be balanced by markers of the writer's authoritative persona. To this end, Hyland exploits the semantic potential of epistemic emphatics or boosters, realizing that an explicit expression of conviction in the truth of the propositional content contributes to his image of a disciplinary insider. Simultaneously he softens the categorical nature of these assertions, guiding the readers towards the preferred interpretations by drawing on factual and empirical evidence rather than on subjectivity-laden arguments. This helps to achieve argumentative consensus with the readers, which is additionally promoted by the incorporation of 
relevant explanations that facilitate the identification of collective sense. The frequent use of hedges and boosters emphasizes Hyland's role as a researcher, which he tries to mitigate by a relatively lower incidence of the other stance devices.

Hyland's economical use of attitudinals and self-mention confirms his expertise in the latest stance-taking repertoires of his own discipline. The scholar restrains himself from advancing arguments based on value-laden attitudes, as these could suggest the partiality of his perspective. However, to remain rhetorically effective, he prudently strengthens the persuasiveness of the presented claims by skilfully shifting between the affective language that is acceptable to other disciplinary insiders and his individual attitudinal resources which enhance his professional assertiveness and reveal excitement at the discussed topics. Hyland gives meaning to his authorial identity by explicitly intruding into his texts when referring to discourse acts and claiming responsibility for elements of research methodology, but takes a more objective stance when reporting research, allowing the empirical data to speak for themselves, which reflects a recent trend in applied linguistics (Hyland \& Jiang, 2016).

The main limitation of this study is the exclusive reliance on the data retrieved from a corpus of Hyland's published writing without juxtaposing it with the scholar's own evaluation of his texts. Nevertheless, this shortcoming opens avenues for future research that could seek an opportunity to interview the renowned academic on the individual ways in which he uses stance devices to project himself into the research papers he writes. It would be also interesting to explore how these preferences have changed throughout Hyland's career, gradually creating the image of an influential academic figure in the discipline of applied linguistics. Given the researcher's reputation and impact on his own field, it is believed that the presented findings provide important implications for novice writers who often feel overwhelmed by the plethora of stance taking devices they may use in their applied linguistics texts. The details of expert performance presented here may serve as a signpost giving direction to the specific rhetorical choices that ensure the appropriate expression of authorial stance and hence contribute to the effective construction of competent scholarly identity within the respective discipline. This kind of stance awareness seems to be more valuable to beginner academics than the mere conviction that apart from conveying content, they should also adequately represent themselves in their writing. 


\section{References}

Abdollahzadeh, E. (2011). Poring over the findings: Interpersonal authorial engagement in applied linguistics papers. Journal of Pragmatics, 43, 288-297. https:// doi.org/ 10.1016/j.pragma.2010.07.019

Abdi, R., Tavangar Rizi, M., \& Tavakoli, M. (2010). The cooperative principle in discourse communities and genres: A framework for the use of metadiscourse. Journal of Pragmatics, 42, 1669-1679. https:// doi.org/ 10.1016/j.pragma.2009.11.001

Akinci, S. (2016). A cross-disciplinary study of stance markers in research articles written by students and experts. (Master's thesis, Iowa State University, Ames, United States). https:/ / lib.dr.iastate.edu/ cgi/ viewcontent.cgi?article=6151\&context=etd

Belladelli, A. (2009). The interpersonal function of going to in written American English. In A. Renouf \& A. Kehoe (Eds.), Corpus linguistics: Refinements and reassessments (pp. 309-325). Rodopi. https:// doi.org/10.1163/9789042025981 017

Biber, D. (1988). Variation across speech and writing. Cambridge University Press. https:// doi.org/ 10.1017/ CBO9780511621024

Biber, D., \& Finegan, E. (1989). Styles of stance in English: lexical and grammatical marking of evidentiality and affect. Text, 9(1), 93-124. https:// doi.org/ 10.1515/ text.1.1989.9.1.93

Biber, D., Johansson, S., Leech, G., Conrad, S. \& Finegan, E. (1999). Longman Grammar of Spoken and Written English. Pearson Education Limited.

Chafe, W. (1986). Evidentiality in English conversation and academic writing. In W. Chafe \& J. Nichols (Eds.), Evidentiality: The linguistic coding of epistemology (pp. 261-272). Ablex.

Charles, M. (2004). The Construction of Stance: A corpus-based investigation of two contrasting disciplines. (Doctoral dissertation, University of Birmingham, Birmingham, United Kingdom). https:/ / www.academia.edu/ 31052804/ THE CONSTRUCTION OF STANCE A CO RPUS-BASED INVESTIGATION OF TWO CONTTRASTING DISCIPLIN̄ES

Clark, R., \& Ivanič, R. (1997). The politics of writing. Routledge.

Conrad, S., \& Biber, D. (2000). Adverbial marking of stance in speech and writing. In S. Hunston \& G. Thompson (Eds.), Evaluation in text: Authorial stance and the construction of discourse (pp. 56-73). Oxford University Press.

Crosthwaite, P., Cheung, L., \& Jiang, F. (2017). Writing with attitude: Stance expression in learner and professional dentistry research reports. English for Specific Purposes, 46, 107-123. https:// doi.org/ 10.1016/j.esp.2017.02.001

Dontcheva-Navrátilová, O. (2009). Evaluation in non-native writer's academic discourse: Stance devices. In I. Hůlková (Ed.), Research in English language teacher education (pp. 33-42). Masarykova Univerzita. 
Dueñas, P. M. (2010). Attitude markers in business management research articles: A cross-cultural corpus-driven approach. International Journal of Applied Linguistics, 20(1), 50-72. https:// doi.org/ 10.1111/j.1473-4192.2009.00228.x

Dueñas, P. M. (2013). Hyland, Ken. In C. A. Chapelle (Ed.), The encyclopedia of applied linguistics (pp. 2846-2849). Blackwell Publishing. https:/ / doi.org/ 10.1002/ $9781405198431 . w b e a l 0518$

Fløttum, K., Dahl, T., \& Kinn, T. (2006). Academic voices: Across languages and disciplines. John Benjamins. https:// doi.org/ 10.1075/pbns.148

Fortanet-Gómez, I. (2004). Verbal stance in spoken academic discourse. In G. Del Lungo Camiciotti \& E. Tognini Bonelli (Eds.), Academic discourse. New insights into evaluation (pp. 99-119). Peter Lang. https:// doi.org/ 10.3726/978-3-0351-0784$\underline{5}$

Gray, B., \& Biber, D. (2012). Current conceptions on stance. In K. Hyland \& C. Sancho Guinda (Eds.), Stance and voice in written academic genres (pp. 15-33). Palgrave. https:// doi.org/ 10.1057/9781137030825.0008

Hinkel, E. (2004). Teaching academic ESL writing. Practical techniques in vocabulary and grammar. Mahwah NJ: Lawrence Erlbaum Associates. https:/ / doi.org/ 10.4324/9781410609427

Hoye, L. (1997). Adverbs and modality in English. Routledge.

Hunston, S., \& Thompson, G. (Eds.). (2000). Evaluation in text. Oxford University Press.

Hyland, K., \& Milton, J. (1997). Qualification and certainty in L1 and L2 students' writing. Journal of Second Language Writing, 6(2), 183-205. https:/ / doi.org/ 10.1016/ s1060-3743(97)90033-3

Hyland, K. (1998a). Boosting, hedging and the negotiation of academic knowledge. Text, 18(3), 349-382. https:// doi.org/10.1515/ text.1.1998.18.3.349

Hyland, K. (1998b). Hedging in scientific research articles. John Benjamins. https:// doi.org/ 10.1075/pbns.54

Hyland, K. (1999). Disciplinary discourses: writer stance in research articles. In C. Candlin \& K. Hyland (Eds.), Writing: Texts, processes and practices (pp. 99-121). Longman. https:// doi.org/ 10.4324/ 9781315840390-6

Hyland, K. (2001a). Humble servants of the discipline? Self-mention in research articles. English for Specific Purposes, 20(3), 207-226. https:/ / doi.org/ 10.1016/ s08894906(00)00012-0

Hyland, K. (2001b). Activity and Evaluation: Reporting practices in academic writing. In J. Flowerdew (Ed.), Academic discourse (pp. 115-113). Routledge. 
Hyland, K. (2004). Disciplinary discourses. Social interactions in academic writing. University of Michigan Press. https:// doi.org/ 10.3998/ mpub.6719

Hyland, K. (2005a). Metadiscourse: Exploring interaction in writing. Continuum.

Hyland, K. (2005b). Prudence, precision, and politeness: hedges in academic writing. Quaderns de Filologia. Estudis Lingüístics, X, 99-112.

Hyland, K. (2005c). Stance and engagement: A model of interaction in academic discourse. Discourse Studies, 7(2), 173-92. https:// doi.org/ 10.1177/1461445605050365

Hyland, K. (2008). Genre and academic writing in the disciplines. Language Teaching, 41(4), 543-562. https:// doi.org/ 10.1017/ s0261444808005235

Hyland, K. (2009). Corpus informed discourse analysis: The case of academic engagement. In M. Charles, D. Pecorari \& S. Hunston (Eds.), Academic writing: At the interface of corpus and discourse (pp. 110-128). Continuum. https:// doi.org/ 10.5040/ 9781474211703.ch-006

Hyland, K. (2011). Disciplines and discourses: social interactions in the construction of knowledge. In D. Starke-Meyerring, A. Paré, N. Artemeva, M. Horne \& L. Yousoubova (Eds.), Writing in the knowledge society (pp. 193-214). Parlor Press.

Hyland, K. (2015). Corpora and written academic English. In D. Biber \& R. Reppen (Eds.), The Cambridge Handbook of English Corpus Linguistics (pp. 292-308). Cambridge University Press. https:// doi.org/ 10.1017/ cbo9781139764377.017

Hyland, K. (2019). Academic interaction: Where's it all going? In K. Hyland \& L.L.C. Wong (Eds.), Specialised English: New directions in ESP and EAP research and practice (pp. 92-106). Routledge. https:// doi.org/ 10.4324/ 9780429492082-8

Hyland, K., \& Jiang, F. K. (2016). Change of attitude? A diachronic study of stance. Written Communication, 33(3), 251-274. https:/ / doi.org/ 10.1177/0741088316650399

Jiang, F. K., \& Hyland, K. (2015). 'The fact that': Stance nouns in disciplinary writing. Discourse Studies, 17(5), 529-550. https:// doi.org/ 10.1177/ 1461445615590719

Leech, G., \& Svatrvik, J. (2002). A Communicative Grammar of English (3rd ed.). Routledge. https:// doi.org/ 10.4324/9781315836041

Ling Lin, K. (2020). Perspectives on the introductory phase of empirical research articles. A study of rhetorical structure and citation use. Springer. https:// doi.org/ 10.1007/978-981-32-9204-8

Martin, J. R., \& White, P. R. R. (2005). The language of evaluation: Appraisal in English. Palgrave Macmillan. https:// doi.org/ 10.1057/9780230511910 
Ochs, E., \& Schieffelin, B. (1989). Language has a heart. Text, 9, 7-25. https:// doi.org/ 10.1515/ text.1.1989.9.1.7

Önder, N. (2012). Metadiscourse use of two prolific researchers in ESP: John Swales and Ken Hyland. In Z. Akşit \& M. Çavuş (Eds.), Embracing Challenges: Proceedings of the 11th METU International ELT Convention (pp. 103-116). Middle East Technical University.

Paquot, M. (2010). Academic vocabulary in learner writing. From extraction to analysis. Continuum. https:// doi.org/ 10.5040/ 9781474211697

Peacock, M. (2006). A cross-disciplinary comparison of boosting in research articles. Corpora, 1(1), 61-84. https:// doi.org/10.3366/ cor.2006.1.1.61

Pho, P. D. (2013). Authorial Stance in research articles. Examples from applied linguistics and educational technology. Palgrave Macmillan. https:// doi.org/ 10.1057/9781137032782

Rozumko, A. (2017). Adverbial markers of epistemic modality across disciplinary discourses: A contrastive study of research articles in six academic disciplines. Studia Anglica Posnaniensia, 52(1), 73-101. https:// doi.org/10.1515/ stap-2017$\underline{0004}$

Sanderson, T. (2008). Corpus, culture, discourse. Gunter Narr.

Scott, M. (2012). WordSmith Tools version 6. Stroud: Lexical Analysis Software.

Simon-Vandenbergen, A-M., \& Aijmer, K. (2007). The semantic field of modal certainty. A corpus-based study of English adverbs. Mouton de Gruyter. https:// doi.org/ 10.1515/9783110198928.fm

Swales, J. (1990). Genre analysis. Cambridge University Press.

Szczyrbak, M. (2014). Of course, indeed or clearly? The interactional potential of modal adverbs in legal genres. SKASE Journal of Theoretical Linguistics, 11(2), 90-102.

Yu, L. S. (2019). A cross-linguistic and cross-cultural study of stance markers in research articles in English and Korean. (Doctoral dissertation, University of Hawai'i, Mãnoa, United States).

https:// scholarspace.manoa.hawaii.edu/ bitstream/10125/66274/Yu hawii 008 5A 10498.pdf

Wang, J., \& Jiang, F. K. (2018). Epistemic stance and authorial presence in scientific research writing: Hedges, boosters and self-mentions across disciplines and writer groups. In P. Mur-Dueñas \& J. Šinkūnienè (Eds.), Intercultural perspectives on research writing (pp. 195-216). John Benjamins. https:// doi.org/10.1075/ aals.18.09wan 


\section{Notes}

1. Full bibliographical details of the corpus texts are available in Hyland's CV at https:/ / uea.academia.edu/ KenHyland/ CurriculumVitae:

a. Numbers of the respective research articles: $24,38,43,52,55,58,65,63,70,71$, $72,73,77,78,80,88,89,91,94,99,109,116,118,119,123,125,127,129,130$, $142,145,154,153,157,161,164,172,173,174,175,176,190,195,198,205$, 209, 215, 221;

b. Numbers of the respective book chapters: $53,68,79,97,101,132,139,152,158$, $168,171,184,186$.

C. Publication dates of the respective books: 2000/2004, 2006;

2. The corpus also includes the following book chapter:

Hyland, K. (2003). Writing and teaching writing. In K. Hyland (Ed.), Second Language Writing (pp. 1-30). Cambridge: Cambridge University Press.

https:// doi.org/ 10.1017/ CBO9780511667251.004 